\title{
IDENTIFICATION AND ASSESSMENT OF THE SEISMIC BEHAVIOUR OF GIOTTO'S BELL TOWER IN FLORENCE (ITALY)
}

\author{
PAOLO SPINELLI ${ }^{1}$ AND MICHELE BETTI ${ }^{*}$ \\ ${ }^{1}$ Department of Civil and Environmental Engineering (DICEA) \\ University of Florence \\ Via di Santa Marta, 3, I-50139, Florence, Italy \\ e-mail: \{paolo.spinelli, michele.betti\}@unifi.it
}

Keywords: Historical Structure, Masonry, Bell tower, FE Model, Seismic behaviour

\begin{abstract}
Among the different typologies of historic buildings, masonry towers represent a hallmark of many European town centres which embody an important heritage to be preserved and passing on to future generations. Giotto's Bell Tower in Florence together with the Leaning Tower of Pisa and the San Marco Tower in Venice (which collapsed in 1902) is one of the iconic masonry towers ever built in Italy. The assessment of the structural behaviour of these structures, together with the development of proper preservation strategies, has attracted in recent decades the interest of a plethora of scholars. Most of the studies on towers vulnerability focuses on the assessment of their seismic behaviour, since their slenderness exposes them to the dynamic effects induced by medium-to-severe earthquakes. This paper, given this background, discusses the identification and the seismic behaviour of Giotto's Bell Tower in Florence. In a first part of this paper a refined numerical model, built through the finite element technique based on a recent laser scanning survey, is reported together with the procedure adopted for its modal identification. The finite element model accounts for the soil-structure-interaction. In a second part of this paper the numerical model is employed to perform linear time-history analyses, by using natural accelerograms. The results of the analyses allow to assess the seismic behaviour of the Bell Tower of Giotto and suggest preservation strategies.
\end{abstract}

\section{INTRODUCTION}

Bell and masonry towers represent a structural typology characteristic of many Italian and European cities. Usually, as for the Florentine case, they are close to churches in the form of tall and slender structures that symbolically characterize and define the image of the historic city. Giotto's Bell Tower in Florence, together with the Leaning Tower of Pisa and the San Marco Tower in Venice (collapsed in 1902), represents one of the most famous bell towers in Italy.

The assessment of the vulnerability and the seismic risk of this particular typology of structures has seen a rapid growth in recent decades, as a result of the interest aroused by them within the scientific community. Recent examples of these studies are: the masonry bell tower of Sant'Andrea in Venice (Italy) [1], the bell tower of the Monza Cathedral (Italy) [2], the Sineo tower (Alba, Italy) [3], a masonry tower of the 8th century, the bell tower of Our 
Lady of Mercy (Valencia, Spain) [4], the bell tower of the Church of Santa Justa and Rufina in Orihuela (Alicante, Spain) [5], and the Ghirlandina Tower in Modena [6].

Research range from experimental works [7] [8] [9] to dynamic identifications [2] [4] [10] [11]. Generally, starting from a field test survey of the current configuration by means of nondestructive and/or weakly destructive experimental tests (e.g. tests with flat jacks, dynamic tests, sonic tests, etc.), numerical models of the structure are built by using the finite element (FE) technique. The numerical models thus created are subsequently employed to analyse the response of the structure due to exceptional load conditions (e.g. earthquake). The purpose of the experimental tests is to estimate the unknown parameters of the numerical models whose calibration is carried out by comparing numerical and experimental results. The type of analysis for which the model is used differs for the analysis methodology used: linear or nonlinear (pushover) static analysis and linear or non-linear time-history analysis [12] [13] [14] [15] [16] [17] [18]. Pushover approaches include both standard methodologies in which the load profile remains constant during the development of the analysis ([15] [17]), and multimodal and/or adaptive approaches, although Peña et al. [14] have shown that the multimodal approach cannot satisfactorily reproduce the collapse phenomena that are activated in masonry towers during the seismic loading). As for the modelling technique, the finite element technique is the most frequently used, allowing an accurate reproduction of the physical geometry of the tower, and the various models differ according to the level of complexity and geometric discretization (from 1D models to 3D models [3] [13]).

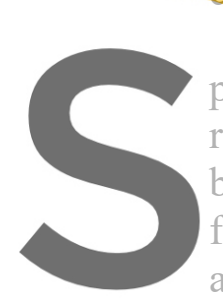

This paper, which
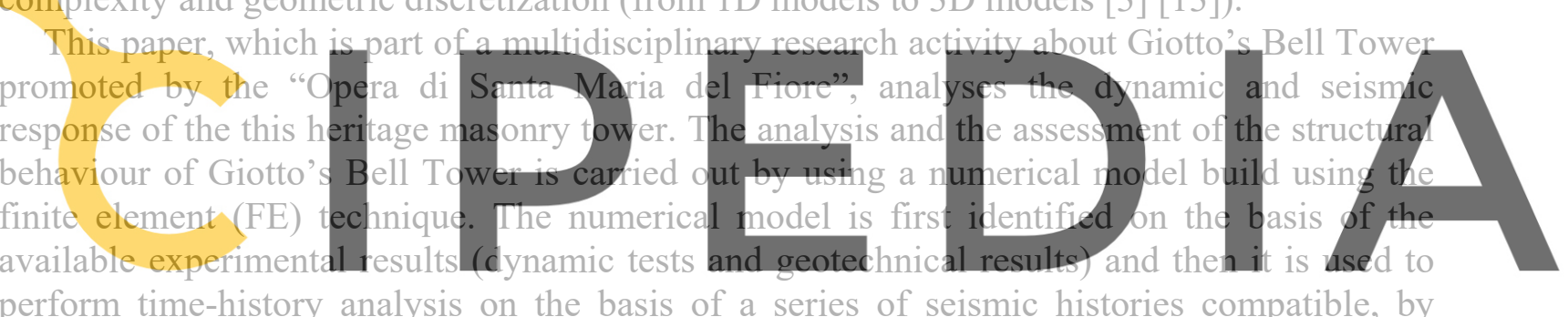

perform time-history analysis on the basis of a series of seismic histories compatible, by

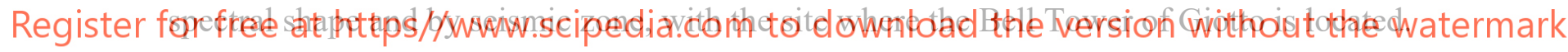

\section{GIOTTO'S BELL TOWER}

During the research activities, different three-dimensional geometric models of Giotto's Bell Tower were built, based on the data gradually recovered during the research. The different geometries have been used to build different numerical models as described below.

A first three-dimensional reconstruction of the geometry was made on the basis of the tables published by Bernardo Sansone Sgrilli in 1733; this geometry was used for the preliminary simulations of the dynamic behaviour of the Bell Tower. Even with the inherent approximations, the numerical model built on the basis of this geometric information allowed to confirm the experimental results obtained by the Pieraccini et al. [20] and Lacanna et al. [21] by providing mode shapes characterized by the first mode shape oriented according to the directions of the main diagonals of the base section.

Subsequently, based on the results of a laser scanner survey, a second three-dimensional reconstruction of the geometry was performed. The geometry allowed the construction of a geometric detailed numerical model that includes: $i$ ) the largest openings in the wall thicknesses; ii) the stairwell inside the masonry walls; iii) the niches and other geometric 
irregularities. The geometric reference model obtained from the laser scanner survey is shown in three-dimensional form in Figure 1a.

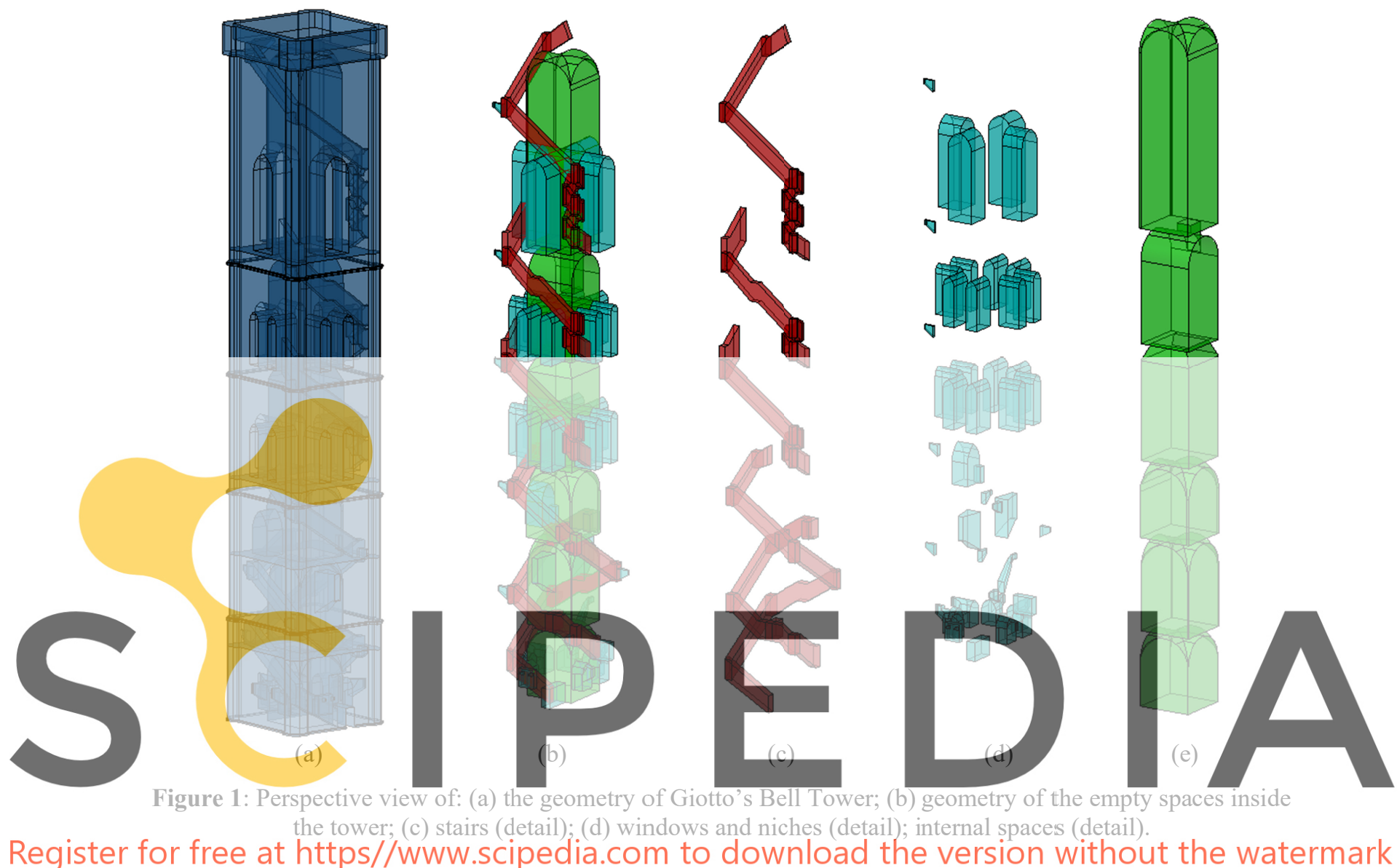

Focusing on the basement of Giotto's Bell Tower, the base section is approximately a square one with a side of about $13 \mathrm{~m}$ and a total thickness of the wall of about $3.3 \mathrm{~m}$. The area of the resistant section at the base is $128 \mathrm{~m}^{2}$, which corresponds to a moment of inertia of $2240 \mathrm{~m}^{4}$ and a radius of inertia $\mathrm{R}=4.18 \mathrm{~m}$. The central core of inertia has a radius $\mathrm{r}=2.70 \mathrm{~m}$. The volume of Giotto's Bell Tower, if the openings inside the walls are not taken into account, is $10800 \mathrm{~m}^{3}$, taking into account the opening and the stairwell it reduces to $9300 \mathrm{~m}^{3}$. The openings (niches, staircases, single and double lancet windows, etc.) have a volume of about $1600 \mathrm{~m}^{3}$, corresponding to $15 \%$ of the total volume.

The geometric representation of these elements is shown in Figure 1b-c.

With respect to the material properties, the walls of Giotto's Bell Tower were built with the multi-leaf technique. The inner face, the only visible, is built with a stone well dressed with regular and squared blocks (of variable dimensions between a minimum of $24 \mathrm{~cm}$ and a maximum of $38 \mathrm{~cm}$ ); the mortar joints are very thin. The inner core, according to the results of the core drilling tests carried out in 2006, is composed of stone aggregates (with dimensions ranging from centimetres to decimetres) and compact lime mortar. The external face, covered by polychrome marbles, does not allow the visual investigation of the wall 
texture. However, it was possible, thanks to the historic photographic documentation of past maintenance/replacement of some of the tiles, to observe the presence of a well-organised and well-preserved brick masonry apparatus.

In the absence, however, of specific tests on the materials, for the elastic and resistance parameters, reference can be made to the values suggested by the Italian standard [22] [23]. Focusing on the following classes: a) "Irregular stone masonry (pebbles, erratic and irregular stone)", b) "Dressed rectangular stone masonry" and c) "Full brick masonry with lime mortar" it can be reasonably assumed a variability of the own weight between 1800 and 2000 $\mathrm{kg} / \mathrm{m}^{3}$. The value of the average compressive strength is more uncertain. The strength of the stone, which forms the internal layer of the walls, can be estimated at about $140 \mathrm{MPa}$. The "Irregular stone masonry" has a compressive strength between 1.0 and $1.8 \mathrm{MPa}$, the "Dressed rectangular stone masonry" has a compressive strength in the range 2.0 3.0 MPa, while "Full brick masonry with lime mortar" has a compressive strength between 6.0 and 8.0 MPa. These values are, overall, low strength values and which are proposed Italian standard for ordinary constructions.

Assuming an average own weight of the masonry of the Bell Tower of Giotto between 1800 and $2000 \mathrm{~kg} / \mathrm{m}^{3}$, depending on the area of the different sections of the bell tower (i.e. different levels), it is possible to estimate the average vertical stress at the various heights. It is possible to observe how the section reductions in correspondence of the windows, in addition to the various anomalies (niches, staircases, compartments, etc.), induce localized alterations in the average value of the vertical stresses. These increases are more visible in the window areas of the up to the section reduction stress at the basement is The reference streng caused by the niches
variable between 1.30
h values proposed by
ns) nay be are overly

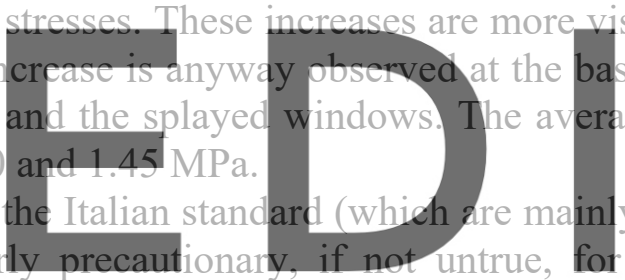
sible in the
gement due
gertical proposed
a historic structure with exceptional characteristics and a careful construction technique such as Giotto's

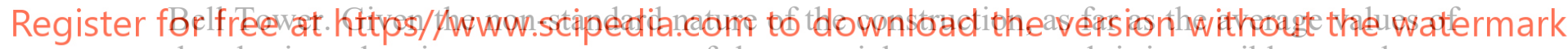
the elastic and resistance parameters of the material are concerned, it is possible to make an expeditious estimate by taking as reference the value of the frequency experimentally obtained. Assuming the tower as a cantilever beam fixed at the basement having prismatic section $A$, height $H$, moment of inertia $J$ and specific weight $\rho$, the frequency of the first mode can be evaluated with the following expression:

$$
f_{1}=\frac{1.875^{2}}{2 \pi} \cdot \frac{1}{H^{2}} \sqrt{\frac{\boldsymbol{E}}{\rho} \frac{\mathrm{J}}{\mathrm{A}}}=f_{\exp }
$$

By inverting Eq. (1), and considering that $f_{\exp }=0.62 \mathrm{~Hz}$ [20] [21], it is possible to estimate the value of modulus of elasticity (E), which results to be equal to 7.2 GPa. From this value, the compressive strength can be estimated using the literature ratios between elastic modulus $E$ and compressive strength $f_{c}$. These ratios vary from about 400 in the case of "Dressed rectangular stone masonry" to about 1000 in the case of new brick masonry. Considering therefore the variability of $\mathrm{E}$ and that of the $\mathrm{E} / \mathrm{fc}$ ratio, the following estimation is obtained:

$$
\mathrm{f}_{\mathrm{c}}=\frac{\boldsymbol{E}}{400 \div 1000}=7.2 \div 18 \mathrm{MPa}
$$


The interpretation of the results of the dynamic tests therefore indicates mechanical parameters of deformability $(E)$ and resistance $\left(f_{c}\right)$ that are much better than the reference values proposed by the Italian standard [23]. These values are compatible with both the excellent state of conservation of Giotto's Bell Tower and the good masonry quality of the structure.

\section{NUMERICAL MODEL AND MODEL UPDATING}

The numerical model built according the laser scanner survey was first employed to perform modal analysis. The results of the experimental dynamic campaign, both frequencies and mode shape [21], were assumed as reference to calibrate the elastic properties of the model, and the identification of the numerical model was performed according two phases, as summarized below.

In a first phase the numerical model (Figure 2a) was assumed to be fixed at the base (fixed base model). The calibration operations led to estimate, as macro-parameters, a total average specific weight of the material of $2000 \mathrm{~kg} / \mathrm{m}^{3}$ and a modulus of elasticity of $7.5 \mathrm{GPa}$ in line, by order of magnitude, with what estimated in the previous paragraph. The results of the identification are summarized in Table 1 where it is possible to observe a good agreement between experimental and numerical results both in terms of frequencies and in terms of identified modes. The percentage differences between experimental and numerical frequencies are around $1 \%$ for the first two modes, with values however lower, or slightly higher, for the higher modes. The comparis on between experimental and numerical mode shape is made in terms adherence is observed forms) which are however affocted by greater
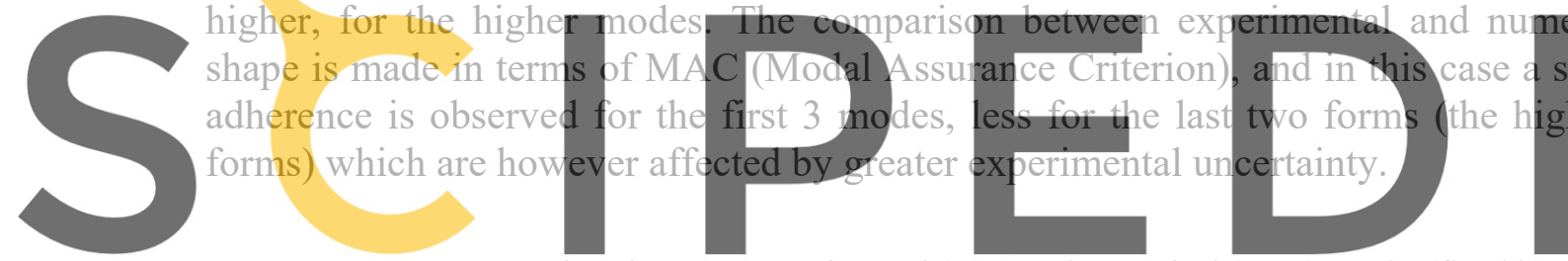

Table 1: Comparison between experimental (Exp) and numerical (Num) results (fixed base model).

Register for free at https//WWMdsqipedia.(fem toughwn loadothe kersion without the watermark

\begin{tabular}{lllll}
\hline 1 & 0.623 & 0.62 & 0.16 & 0.99 \\
\hline 2 & 0.647 & 0.64 & 1.20 & 0.99 \\
\hline 3 & 2.543 & 2.65 & 4.40 & 0.95 \\
\hline 4 & 3.081 & 3.17 & 3.10 & 0.72 \\
\hline 5 & 3.156 & 3.19 & 1.20 & 0.77 \\
\hline
\end{tabular}

Table 2: Comparison between experimental (Exp) and numerical (Num) results (SSI).

\begin{tabular}{ccccc}
\hline Mode \# & Exp $(\mathrm{Hz})$ & Num $(\mathrm{Hz})$ & $\Delta(\%)$ & MAC \\
\hline 1 & 0.623 & 0.62 & 0.16 & 0.99 \\
\hline 2 & 0.647 & 0.63 & 1.90 & 0.97 \\
\hline 3 & 2.543 & 3.06 & 17.0 & 0.82 \\
\hline 4 & 3.081 & 3.35 & 8.20 & 0.76 \\
\hline 5 & 3.156 & 3.38 & 6.70 & 0.83 \\
\hline
\end{tabular}

In a second phase the soil-structure interaction (SSI) has been taken into account, removing the hypothesis of rigid soil (Figure 2b). The soil was modelled with a series of elastic springs 
whose impedances were estimated during the studies conducted on the geotechnical aspects. The impedances assigned to the elastic springs, simulating the interaction of the soil with the structure, were the following: $\mathrm{K}_{X}=21.20 \mathrm{GN} / \mathrm{m} ; \mathrm{K}_{\mathrm{Z}}=50.90 \mathrm{GN} / \mathrm{m}$ and $\mathrm{K}_{\mathrm{R}}=2278 \mathrm{GNm} / \mathrm{rad}$. The results of the identification of the SSI model are summarized in Table 2. It is possible to observe that to account for the soil-structure interaction leads, in terms of elastic parameters of the identified model, to the following results: $i$ ) a reduction of the estimated own weight that, while remaining within the estimated physical parameters, decreases from $2000 \mathrm{~kg} / \mathrm{m}^{3}$ to $1800 \mathrm{~kg} / \mathrm{m}^{3}$ and ii) an increase of the value of the modulus of elasticity that moves from 7.5 GPa to $9.0 \mathrm{GPa}$.

Globally this corresponds to an increase in the $\mathrm{E} / \rho$ ratio, i.e. an increase of the velocity of the velocity of propagation of the elastic compression waves (P-waves) as expected.
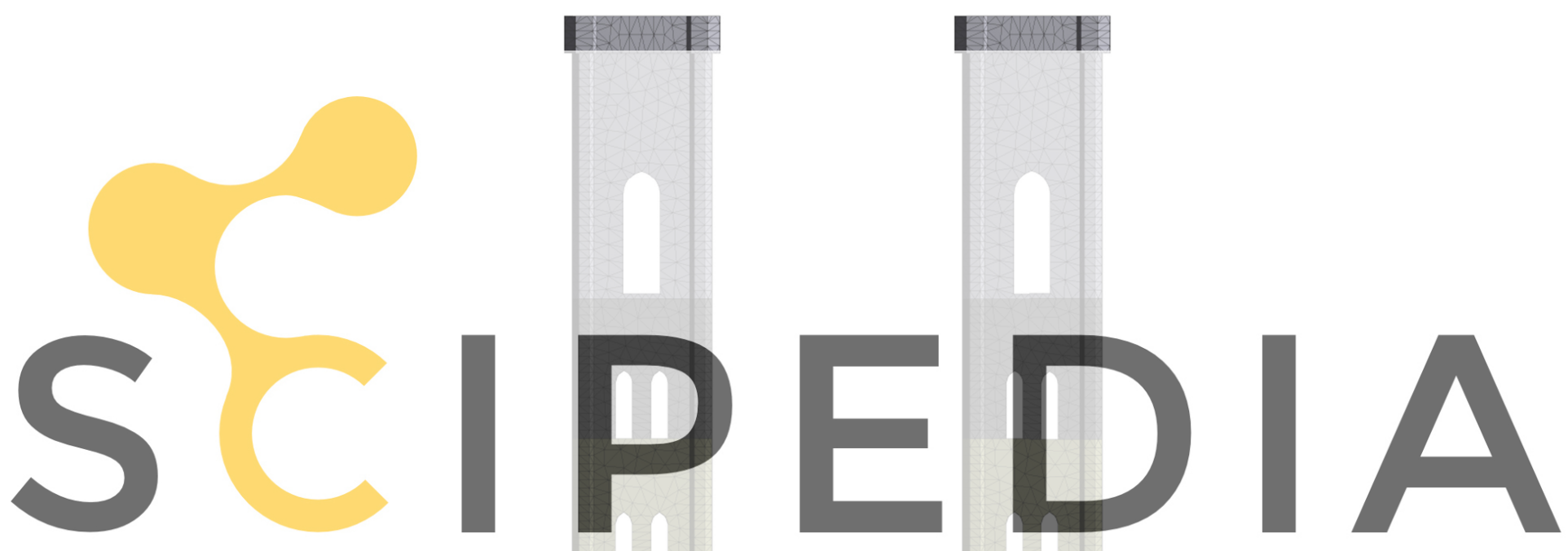

Register for free at https//www.scipedia.com to download the version without the watermark

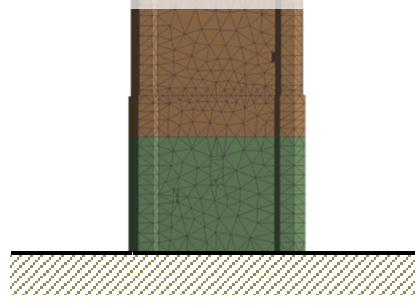

a- fixed base model

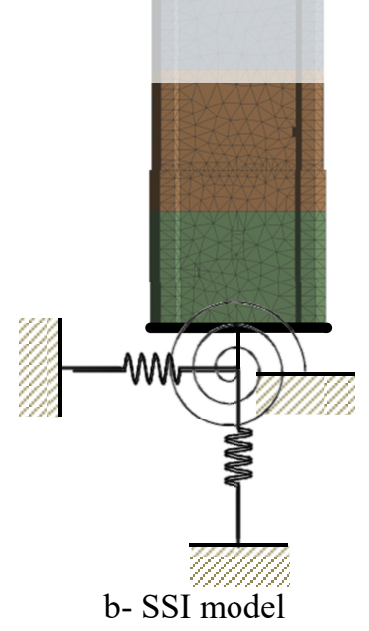

Figure 2: FE model. 


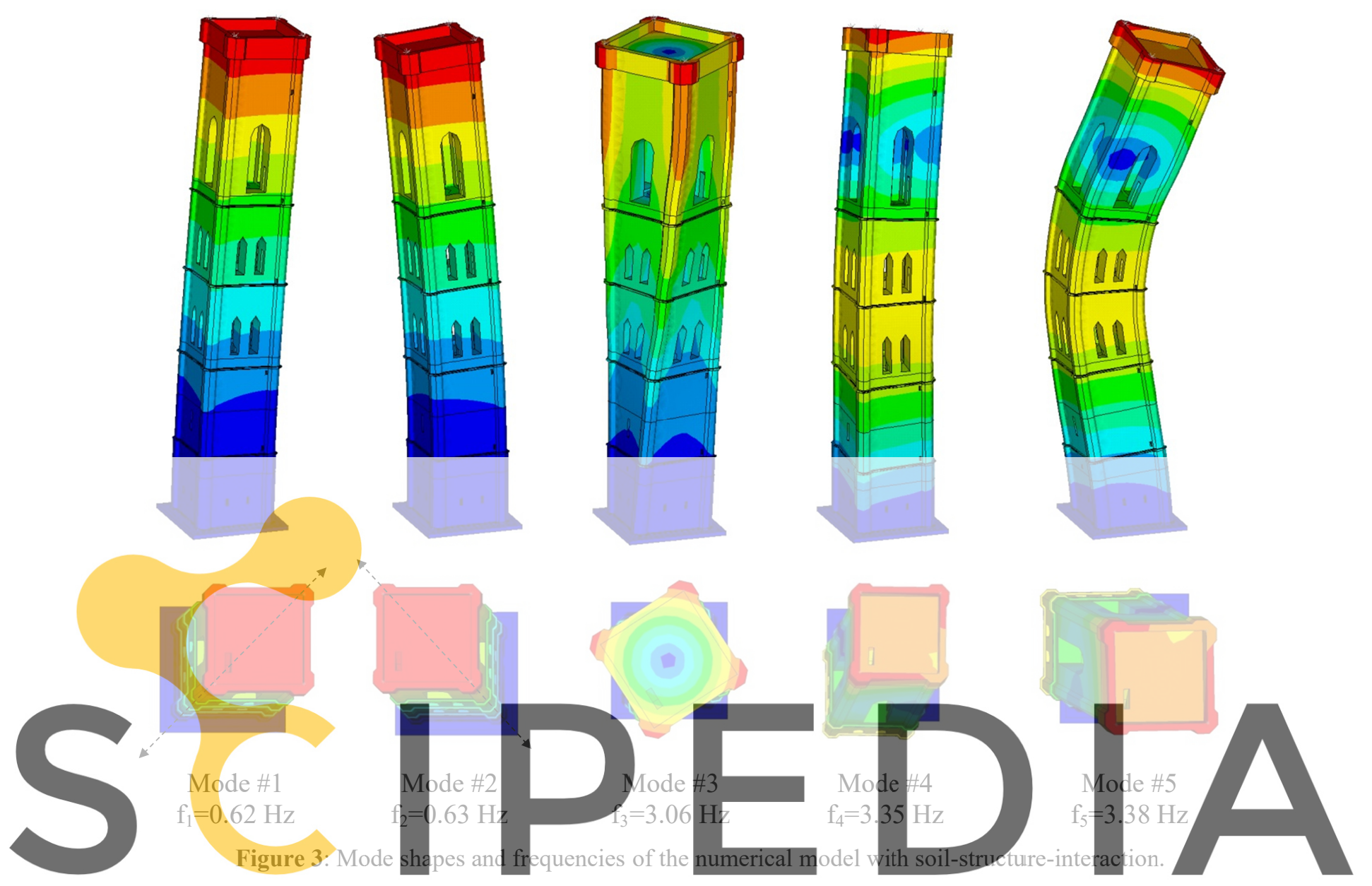

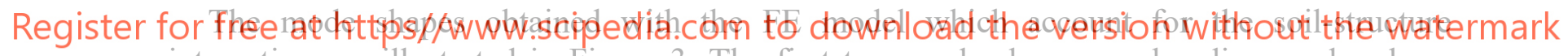
interaction are illustrated in Figure 3. The first two mode shapes are bending mode whose direction is oriented according to the main diagonals of the base section (and represented with a dashed line in Figure 3).

\section{SEISMIC BEHAVIOUR}

The FE model, identified in order to reproduce the experimental dynamic measurements, and inclusive of the soil-structure interaction (SSI, Figure 3), was used to perform timehistory analysis by using a series of natural records selected during the research. Given the spatial variability of the mechanical parameters, the uncertainties still existing on the characterization of the material strength domains and the local effects that can be due to the multi-leaf nature of the masonry walls, the numerical model was here used to perform linear elastic analyses.

The 7 natural accelerograms selected for this study are reported in Figure 4; all the accelerograms were scaled to the maximum peak ground acceleration representative of the site hazard $(0.16 \mathrm{~g})$. It is interesting to observe that if the frequency content of the natural records is calculated it almost never affects the first two natural frequencies of Giotto's Bell 
Tower. On the contrary, contributions can be found on the upper mode shapes which interest the higher bending modes (modes \#4 and \#5).
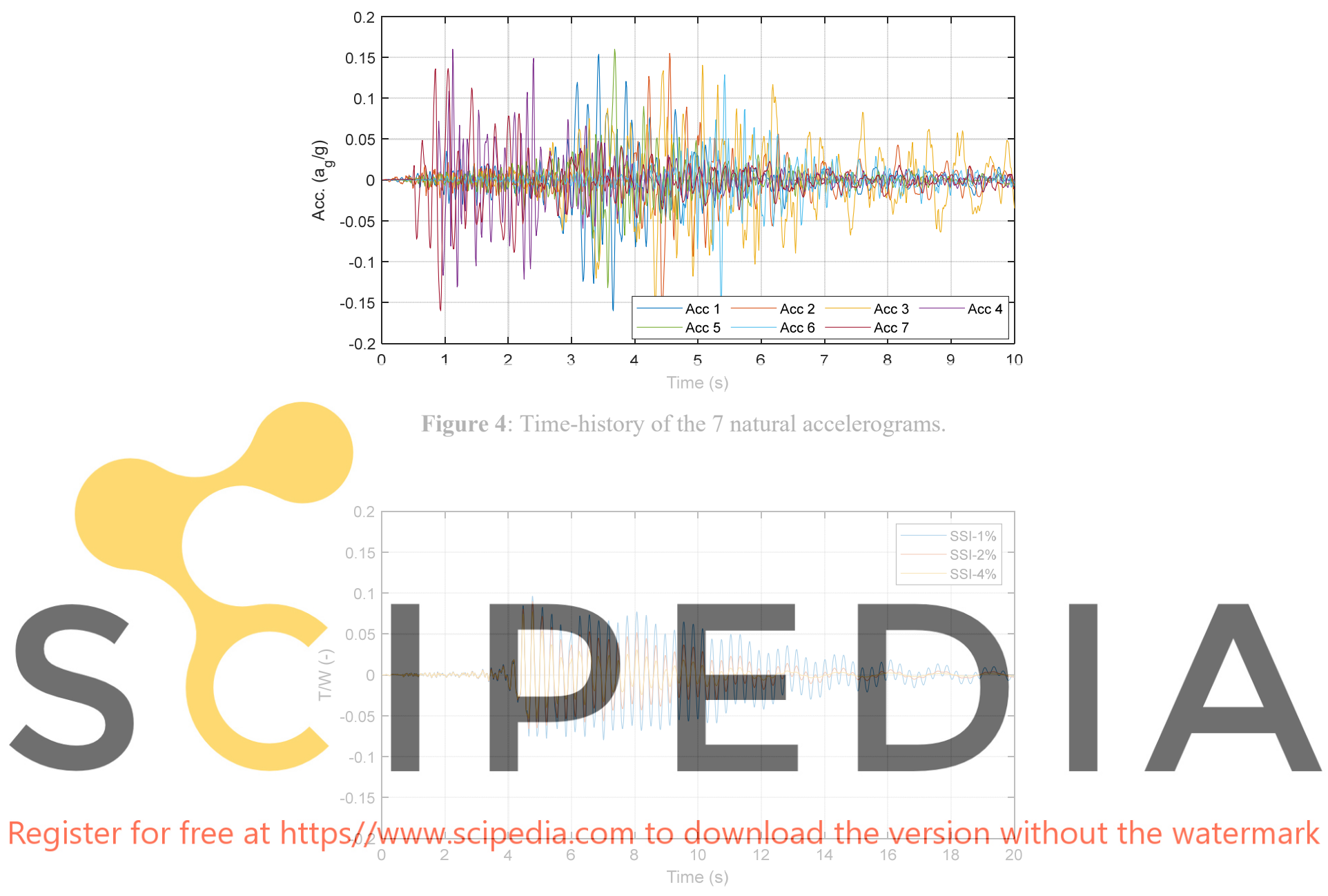

Figure 5: Base shear for three cases of damping: $4 \%, 2 \%$ and $1 \%$.

The 7 natural accelerograms have thus been applied both in the two main directions of the base section of Giotto's Bell Tower, and in the two directions of the main diagonals. As an example, Figure 5 shows, when the natural record "Acc 2" is considered and applied along with one of the main directions, the evolution over time of the base shear (divided by the weight of the Bell Tower) for different values of structural damping. Three cases of damping were investigated $(4 \%, 2 \%$ and $1 \%)$ since, given the isostatic nature of the tower, this is a relevant parameter in its seismic response. The time-history of the accelerations (for a damping equal to $2 \%$.) as obtained at the different height of the Bell Tower of Giotto is reported in Figure 6, where it is possible to appreciate the amplification over the height of the base accelerations. The analysis of all the results shows a differentiated dynamic response between the first levels of Giotto's Bell Tower and the last one (the bell cell) and it is interesting to observe that time-history response of the tower is dominated by superior modes. 


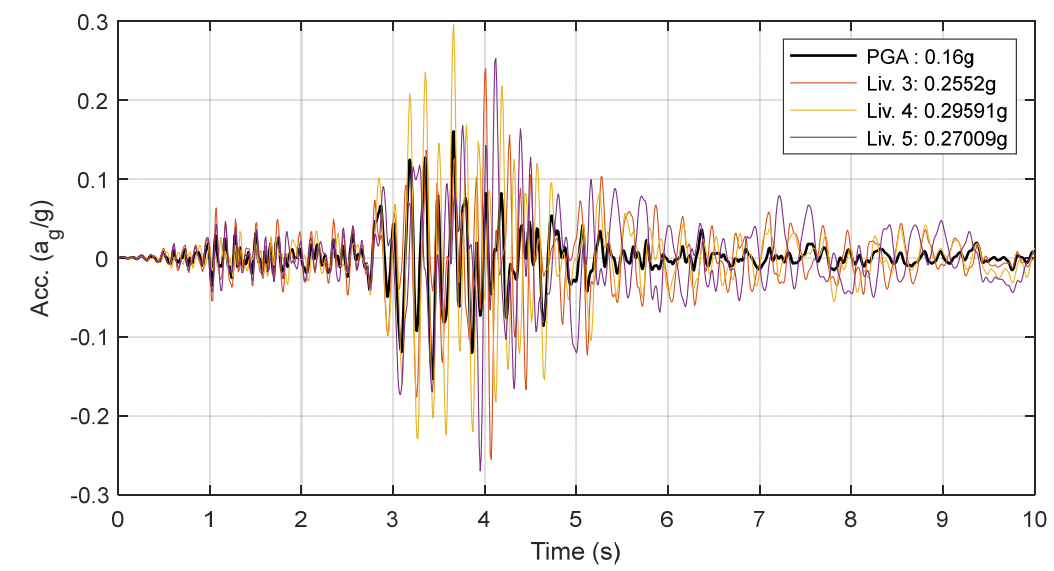

Figure 6: Base shear for three cases of damping: $4 \%, 2 \%$ and $1 \%$.

Table 3: Time-history: synthesis of the results.

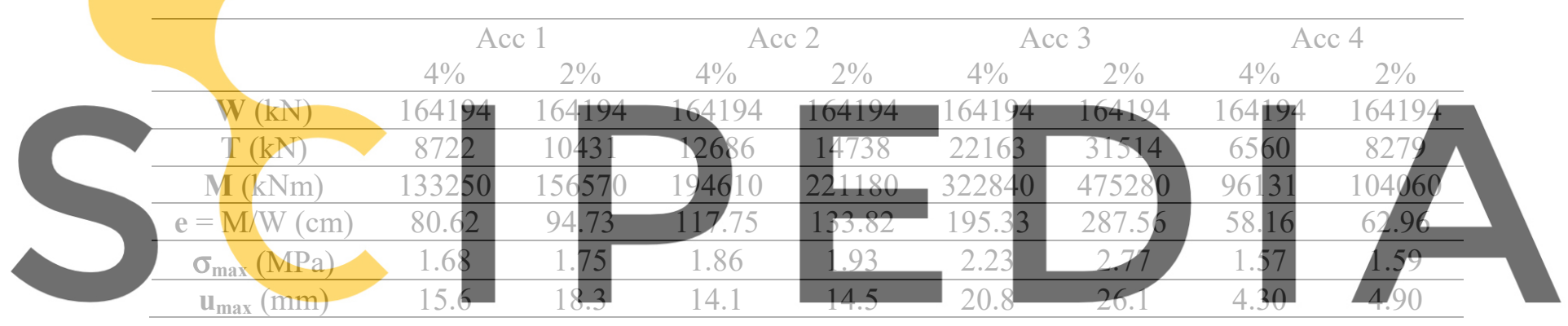

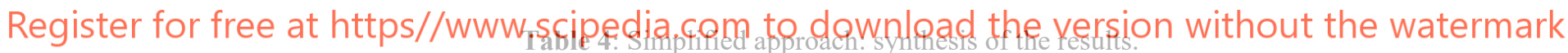

\begin{tabular}{cccccc}
\hline & CR.A3062 & IT.FHC & IT.SPT1 & IT.MUGew & NTC2008 \\
\hline $\mathbf{W}(\mathrm{kN})$ & 164194 & 164194 & 164194 & 164194 & 164194 \\
\hline $\mathbf{T}(\mathrm{kN})$ & 319 & 1104 & 1057 & 2497 & 19834 \\
\hline $\mathbf{M}_{\mathbf{d}}(\mathrm{kNm})$ & 17850 & 61815 & 59170 & 139827 & 396672 \\
\hline $\mathbf{M}_{\mathbf{c}}(\mathrm{kNm})$ & 1005649 & 1005649 & 1005649 & 1005649 & 1005649 \\
\hline $\mathrm{M}_{\mathrm{d}} / \mathrm{M}_{\mathrm{c}}$ & 0.02 & 0.06 & 0.06 & 0.14 & 0.39 \\
\hline $\mathbf{e}=\mathrm{M} / \mathrm{W}(\mathrm{cm})$ & 11 & 37 & 36 & 85 & 240 \\
\hline$\sigma_{\max }(\mathrm{MPa})$ & 1.34 & 1.47 & 1.46 & 1.70 & 2.44 \\
\hline $\mathbf{u}_{\max }(\mathrm{mm})$ & 1.7 & 5.9 & 5.7 & 13.5 & 38.2 \\
\hline
\end{tabular}

Overall, the results obtained with the time-history analyses are summarized in Table 3 for the first 4 natural accelerograms for two different damping values ( 4 and $2 \%$ ). The cases not included in the table offer similar results to the case 4 and therefore have not been reported.

From the results reported in the table, which offer a synthesis of the results obtained with all the (linear) time-history analyses, it can be observed that in almost all cases during the development of the seismic load the pressure centre at the base of Giotto's Bell Tower always 
remains inside the central core of inertia $(\mathrm{r}=270 \mathrm{~cm})$. Only in the case of accelerogram \#3, for a damping of $2 \%$ a value of $\mathrm{e}=287 \mathrm{~cm}$ slightly greater than the core radius is observed. The corresponding maximum normal stress, evaluated with the no-tension material scheme, is $2.77 \mathrm{MPa}$ lower, however, than the estimated resistance values (which has been estimated between 7.2 and $18 \mathrm{MPa}$ ).
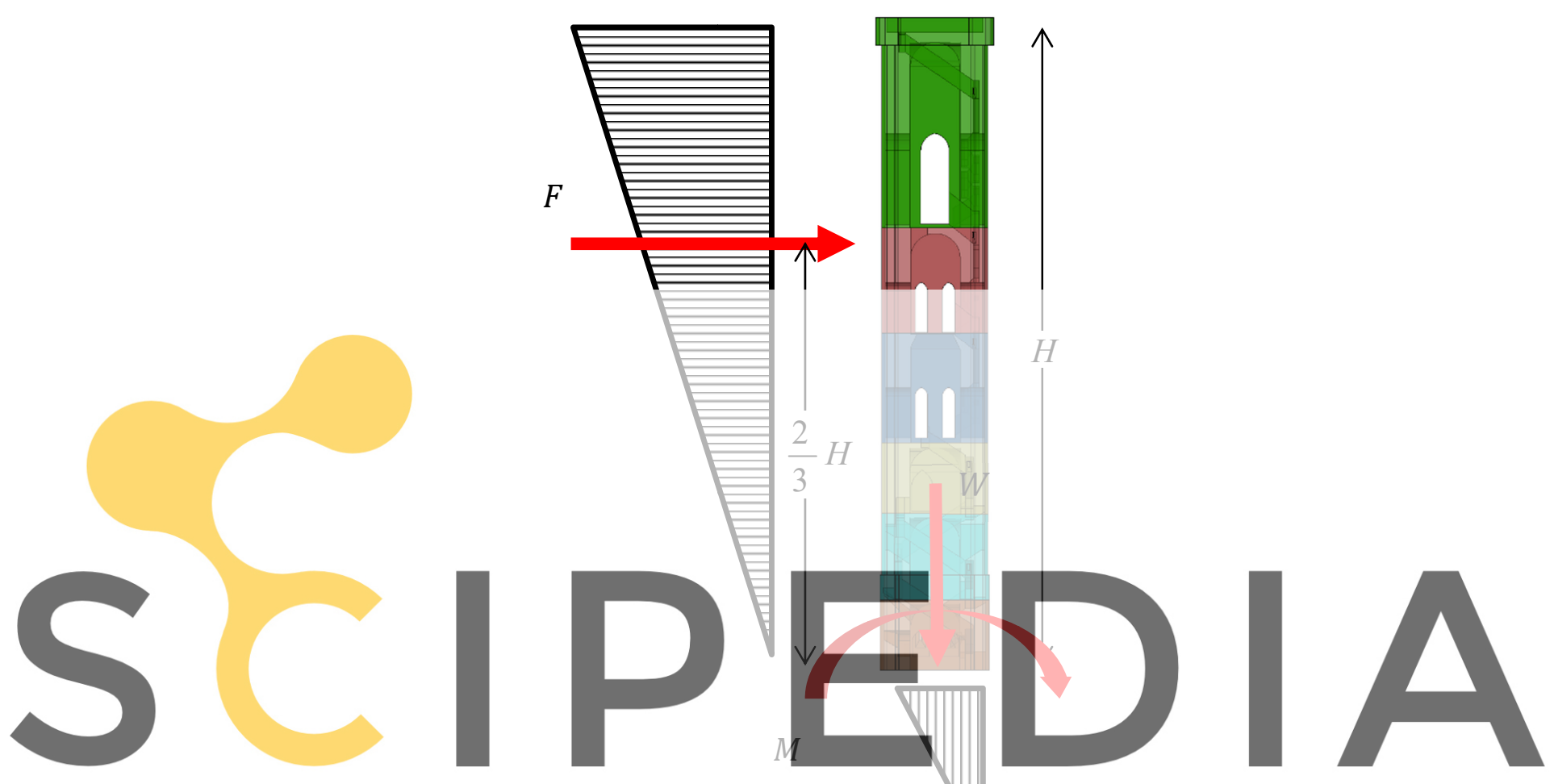

\section{Register for free at https//www.scipedia.com to download the version without the watermark}

Figure 7: Static distribution of equivalent seismic actions.

As an example, and in a simplified way, the provisions of the Italian standard (valid for ordinary buildings) have been examined, and the actions induced by an earthquake have been evaluated according to the scheme of cantilever masonry beam shown in Figure 7. According to this simple scheme, starting from the spectral ordinate of the elastic response spectrum in correspondence of the fundamental mode of the structure, it is possible to determine, expeditiously, the loads (base shear $\mathrm{T}$ and bending moment $\mathrm{M}$ ) induced by the expected earthquake (the Life Safety limit state with a return period of the seismic action equal to 712 years was considered) on Giotto's Bell Tower by the following:

$$
F=\mathrm{S}_{a}\left(T_{1}\right) \cdot \frac{W}{q g} ; \mathrm{M}=F \cdot \frac{2}{3} H
$$

The results obtained with this simplified approach are summarised in Table 4 where the results obtained considering the seismic hazard provided by the Italian standard are also compared with the one provided assuming the spectra derived by some of the natural records employed for the time-history analyses. 
Since the spectra derived from the natural accelerograms have modest spectral ordinates (and in any case well below the ordinates of elastic response spectrum which is derived from conservative choices, based on the envelope criterion of deterministic spectra) they provide the lowers values. In general it is possible to observe that: $i$ ) the fundamental period of Giotto's Bell Tower is in the tail of the spectra; ii) the spectral ordinate of the spectra obtained from the natural accelerograms, measured in correspondence to the fundamental period of the Bell Tower of Giotto, is about one order of magnitude lower than the one of the standard. These elements justify the summary values of the results reported in Table 4.

The analyses here summarized represent a first contribution to the understanding of the seismic behaviour of the Giotto Bell Tower; the assessment of the structural behaviour of the monument under exceptional or long-lasting loads will in any case require the refinement of further modelling strategies, including modelling techniques with appropriate non-linear constituent laws and, possibly, the development of a long-term continuous monitoring necessary for the updating and validation of future numerical models. The analytical approach to be used to assess the structural behaviour of complex monumental buildings can in fact only proceed step-by-step, where possible additional research and analysis are identified based on the results of previous numerical and experimental analyses.

\section{CONCLUSIONS}

This paper summarized some of the results that have emerged regarding the dynamic identification and the seismic assessment of Giottos' Bell Tower. The numerical models developed during the research made possible, thanks to the results of an articulated analysis and survey campaign promoted by the "Opera di Santa Maria del Fiore", to reproduce and interpret the static and dynamic behaviour of Giotto's Bell Tower. The availability of a detailed geometric survey has allowed an accurate reproduction of the geometry of the tower with its main irregularities; the availability of a series of dynamic tests has allowed, together with the results of the geotechnical investigations, to identify and estimate some of the unknown parameters of the numerical model. The analyses carried out with the numerical model, and validated by means of a simple scheme, although carried out in a linear elastic field due to the uncertainties still existing, did not reveal any specific critical configuration in the structure.

In the static field, considering the effects of self-weight, the numerical model provides average values of the vertical stresses at the different levels well below the strength values of the materials (estimated on the basis of the results of the dynamic tests). With respect to the effects of the seismic loads both linear time-history analyses (by assuming natural ground accelerograms) and simplified static analyses were performed. On the whole, the analyses did not show critical configurations. In fact, the frequencies of the Bell Tower of Giotto are on the tail of the elastic spectrum, and the spectral ordinates of the selected natural accelerograms are much lower than the one of the standard.

Although the analyses carried out have not revealed any critical configuration, they suggest: $i$ ) the implementation of a long-term monitoring system with accelerometers in order to better characterize the dynamics behaviour of the structure (with particular interest for the higher modes of Giotto's Bell Tower given their relevance in the global seismic response); ii) additional experimental and numerical investigations aimed to assess the effect induced by the 
swinging of the bells; iii) the investigation, given the sensitivity of the dynamic response to structural damping, of a tuned mass damping system (TMD) built by using the bell masses in the bell cell.

Acknowledgements. This research was financially supported by the "Opera di Santa Maria del Fiore" (which promoted a campaign of studies about Giotto's Bell Tower in 2017), that is gratefully acknowledged.

\section{REFERENCES}

[1] Russo, G., Bergamo, O., Damiani, L. and Lugato, D. Experimental analysis of the Saint Andrea Masonry Bell Tower in Venice. A new method for the determination of Tower Global Young's Modulus E. Engineering Structures (2010) 32(2):353-360.

[2] Gentile, C. and Saisi, A. Ambient vibration testing of historic masonry towers for structural identification and damage assessment. Construction and Building Materials (2007) 21(6):1311-1321.

[3] Carpinteri, A., Invernizzi, S. and Lacidogna, G. Numerical assessment of three medieval masonry towers subjected to different loading conditions. Masonry International (2006) 19:65-76.

[4] Ivorra, S. and Pallares, F.J. Dynamic investigations on a masonry bell tower. Engineering Structures (2006) 28(5):660-667.

[5] Ivorra, S., Pallarés, F.J. and Adam, J.M. Experimental and numerical results from the seismic study of a masonry bell tower. Advances in Structural Engineering (2009) 12(2):287-293.

[6] Sabia, D., Aoki, T., Cosentini, R.M. and Lancellotta, R. Model updating to forecast the dynamic behavior of the Ghirlandina tower in Modena, Italy. Journal of Earthquake Engineering (2015) 19(1):1-24.

[7] Binda, L., Zanzi, L., Lualdi, M. and Condoleo, P. The use of georadar to assess damage to a masonry bell tower in Cremona, Italy. NDT \& E International (2005) 38(3):171179.

[8] Anzani, A., Binda, L., Carpinteri, A., Invernizzi, S. and Lacidogna, G. A multilevel approach for the damage assessment of historic masonry towers. Journal of Cultural Heritage (2010) 11(4):459-470.

[9] Bartoli, G., Betti, M. and Giordano, S. In situ static and dynamic investigations on the "Torre Grossa" masonry tower. Engineering Structures (2013) 52:718-733.

[10] Ramos, L.F., Marques, L., Lourenço, P.B., De Roeck, G., Campos-Costa, A. and Roque, J. Monitoring historical masonry structures with operational modal analysis: Two case studies. Mechanical Systems and Signal Processing (2010) 24(5):1291-1305.

[11] Pieraccini, M., Dei, D., Betti, M., Bartoli, G., Tucci, G. and Guardini, N. Dynamic identification of historic masonry towers through an expeditious and no-contact approach: application to the "Torre del Mangia" in Siena (Italy). Journal of Cultural Heritage (2014) (2014) 15(3):275-282.

[12] Casolo, S. A three dimensional model for vulnerability analyses of slender masonry Medieval towers. Journal of Earthquake Engineering (1998) 2(4):487-512.

[13] Bernardeschi, K., Padovani, C. and Pasquinelli, G. Numerical modelling of the structural behaviour of Buti's bell tower. Journal Cultural Heritage (2004) 5:371-378. 
[14] Peña, F., Lourenço, P.B., Mendez, N. and Oliveira, D. Numerical models for the seismic assessment of an old masonry tower. Engineering Structures (2010) 32:1466-1478.

[15] Milani, G., Casolo, S., Naliato, A. and Tralli, A. Seismic assessment of a medieval masonry tower in Northern Italy by limit, non-linear static and full dynamic analyses. International Journal Architectural Heritage (2012) 6(5):489-524.

[16] D'Ambrisi, A., Mariani, V. and Mezzi, M. Seismic assessment of a historical masonry tower with nonlinear static and dynamic analyses tuned on ambient vibration tests. Engineering Structures (2012) 36:210-219.

[17] Casolo, S., Milani, G., Uva, G. and Alessandri, C. Comparative seismic vulnerability analysis on ten masonry towers in the coastal Po Valley in Italy. Engineering Structures (2013) 49:465-90.

[18] Ferrante, A., Clementi, F., Milani, G. Advanced numerical analyses by the Non-Smooth Contact Dynamics method of an ancient masonry bell tower. Mathematical Methods in the Applied Sciences (2020) 1-20.

[19] Bru, D., Ivorra, S., Betti, M., Adam, J.M., and Bartoli, G. Parametric dynamic interaction assessment between bells and supporting slender masonry tower. Mechanical Systems and Signal Processing (2019) 129: 235-249.

[20] Pieraccini, M., Fratini, M., Dei, D., and Atzeni, C. Structural testing of Historical Heritage Site Towers by microwave remote sensing. Journal of Cultural Heritage (2009) 10: 174-182.

[21] Lacanna, G., Ripepe, M., Coli, M., Genco, R., and Marchetti, E. Full structural dynamic response from ambient vibration of Giotto's bell tower in Firenze (Italy), using modal analysis and seismic interferometry. NDT and E International (2019) 102: 9-15.

[22] NTC 2008, Nuove Norme Tecniche per le Costruzioni, G.U. n. 29, 4 Febbraio 2008, S.O. n. 30. D.M. del Ministero delle Infrastrutture e dei Trasporti 14 Gennaio 2008 (in Italian).

[23] MIT 2009, Circolare n. 617 del 2 febbraio 2009. Istruzioni per l'Applicazione Nuove Norme Tecniche Costruzioni di cui al Decreto Ministeriale 14 gennaio 2008 (in Italian). 